\title{
Angular Sensitivity of Gated Micro-Channel Plate Framing Cameras
}

O. L. Landen, A. Lobban, T. Tutt, P. M. Bell, R. Costa, and F. Ze

This article was submitted to $13^{\text {th }}$ Topical Conference on High Temperature Plasma Diagnostics, Tucson, AZ, June 19-23, 2000

\section{July 24, 2000}

Lawrence

Livermore

National

Laboratory 


\section{DISCLAIMER}

This document was prepared as an account of work sponsored by an agency of the United States Government. Neither the United States Government nor the University of California nor any of their employees, makes any warranty, express or implied, or assumes any legal liability or responsibility for the accuracy, completeness, or usefulness of any information, apparatus, product, or process disclosed, or represents that its use would not infringe privately owned rights. Reference herein to any specific commercial product, process, or service by trade name, trademark, manufacturer, or otherwise, does not necessarily constitute or imply its endorsement, recommendation, or favoring by the United States Government or the University of California. The views and opinions of authors expressed herein do not necessarily state or reflect those of the United States Government or the University of California, and shall not be used for advertising or product endorsement purposes.

This is a preprint of a paper intended for publication in a journal or proceedings. Since changes may be made before publication, this preprint is made available with the understanding that it will not be cited or reproduced without the permission of the author.

This report has been reproduced directly from the best available copy.

Available electronically at http://www.doc.gov/bridge

Available for a processing fee to U.S. Department of Energy

And its contractors in paper from

U.S. Department of Energy

Office of Scientific and Technical Information

P.O. Box 62

Oak Ridge, TN 37831-0062

Telephone: (865) 576-8401

Facsimile: (865) 576-5728

E-mail: reports@adonis.osti.gov

Available for the sale to the public from

U.S. Department of Commerce

National Technical Information Service

5285 Port Royal Road

Springfield, VA 22161

Telephone: (800) 553-6847

Facsimile: (703) 605-6900

E-mail: orders@ntis.fedworld.gov

Online ordering: http:/ / www.ntis.gov/ordering.htm

\section{OR}

Lawrence Livermore National Laboratory

Technical Information Department's Digital Library

http: / / www.llnl.gov/tid/Library.html 


\title{
Angular sensitivity of gated micro-channel plate framing cameras*
}

\author{
O. L. Landen, A. Lobban, T. Tutt, P. M. Bell, R. Costa, and F. Ze
}

Lawrence Livermore National Laboratory

P.O. Box 5508, Livermore, CA 94551

\begin{abstract}
Gated, microchannel-plate-based (MCP) framing cameras have been deployed worldwide for 0.2 - $9 \mathrm{keV}$ x-ray imaging and spectroscopy of transient plasma phenomena. For a variety of spectroscopic and imaging applications, the angular sensitivity of MCPs must be known for correctly interpreting the data. We present systematic measurements of angular sensitivity at discrete relevant photon energies and arbitrary MCP gain. The results can been accurately predicted by using a simple 2D approximation to the $3 \mathrm{D} \mathrm{MCP}$ geometry and by averaging over all possible photon ray paths.
\end{abstract}

*Work performed under the auspices of the U.S. Department of Energy by the University of California Lawrence Livermore National Laboratory under contract number W-7405-ENG-48. 


\section{Introduction}

Microchannelplate (MCP) $\mathrm{x}$-ray detectors are in routine use at all large laserplasma facilities ${ }^{1-5}$. Typically, the average $x$-ray incidence angle is at $6-8^{\circ}$ to the pore axis to maximize sensitivity $(\sim \cot \theta)$ while avoiding bore-sighted operation. However, significant departures from this incidence angle is present for at least two types of experiments; those using Bragg diffraction spectrometers ${ }^{6}$ and those using wide angular field-of view point projection imaging7. Present and future MCP users either need complete information on the angle-dependent sensitivity of these MCPs at all relevant photon energies, or predictive capabilities based on modelling validated by a few select measurements, as described here. Previous characterization ${ }^{8-13}$ has addressed dc nonimaging applications under unspecified MCP gain conditions, with limited data at the multi-keV photon energies relevant to ICF and high energy density physics. In addition, by varying the gain on the plate, we are able to confirm the transition from single surface photoelectron production at low photon energies $(<2 \mathrm{keV})$ to multiple, distributed $x$-ray-pore interactions at penetrating higher photon energies $(>5 \mathrm{keV})$. Finally, the relative photoelectron production efficiency between the gold conductive ends and the leaded glass matrix is inferred from the angular sensitivity.

\section{Model}

The conceptual operation of a MCP is shown in Fig. 1. The entrance plane of the MCP is negatively biased relative to the exit plane. X-rays incident at an angle $\theta$ relative to the pore axis produce photoelectrons in the non-conductive leaded glass pore walls. These photoelectrons in turn generate secondary electrons; those that escape the wall are accelerated downwards by the electric field. Their initial radial momentum leads to collisions with the opposing wall, where they liberate more electrons leading to 
an amplifying cascade process. The response per unit area, $Q$, of the micro- channel plate can be expressed as:

$$
Q \sim\left(\frac{S(E) R(E) \cot \theta}{m f p(E)}\right)_{j} \sum_{n} I_{n} G_{n}
$$

were $I_{n}$ and $G_{n}$ are the remaining x-ray flux and MCP gain after traversing $n$ pore walls, $\mathrm{R}$ is the primary photoelectron range, $\mathrm{S}$ is the number of secondary electrons produced / photoelectron, $\theta$ is the angle between the incident $\mathrm{x}$-ray and the pore axis, and $\mathrm{mfp}$ is the $\mathrm{x}$-ray mean-free path in the MCP material. The response is the sum over $\mathrm{n}$ pore interactions and many possible $x$-ray paths $\mathrm{j}$ as shown in Fig. 1, some entering through the top of the MCP, some entering through the wall. The 3D hexagonally-packed pore structure is modelled here as 2D ridges to speedup computation (see Fig. 2). For example, a typical MCP with 10- $\mu$ m-diameter pores spaced center-to-center by $\mathrm{D}=12$ $\mu \mathrm{m}$ is modelled here as $7.6 \mu \mathrm{m}$-wide channels spaced by $12 \mu \mathrm{m}$, preserving the average pore wall thickness $\mathrm{d}$. When the photoelectron range $\mathrm{R}$ is $>1 / 2$ the average pore wall thickness $\mathrm{d}(\approx 2 \mu \mathrm{m})$, which typically occurs for photon energies ${ }^{11}$ above $15 \mathrm{keV}$, then $\mathrm{R}$ in Eq. (1) should be replaced by $d / 2$. The flux $I_{n}$ is given by Beers law as:

$$
I_{n}=I_{0} \exp ^{-(n d / m f p \sin \theta)}
$$

where $\mathrm{d}$ is the average pore wall thickness. The photon mean free path vs photon energy E for a typical typical leaded glass MCP composition ${ }^{14}$ is shown in Fig. 3. The mfp increases approximately as $\mathrm{E}^{2}$ except for structure at the $\mathrm{Ba} \mathrm{M}, \mathrm{Si} \mathrm{K}$ and $\mathrm{Pb}$ L edges at 1, $2 \mathrm{keV}$ and $12-15 \mathrm{keV}$, respectively. 
The position dependent gain $G_{n}$ is given by the discrete dynode gain $\operatorname{mode} l^{15}$ as:

$\mathrm{G}_{\mathrm{n}}(\mathrm{x})=\left(\mathrm{V} / \mathrm{V}_{0}\right)^{\mathrm{L} / 4 \mathrm{D}(1-\mathrm{x} / \mathrm{L})}$

where $\mathrm{V}$ is the $\mathrm{MCP}$ bias voltage, $\mathrm{V}_{0}$ the voltage providing unity gain (typically $400-500$ $\mathrm{V}), \mathrm{L}$ and $\mathrm{D}$ are the pore length and diameter respectively, and $\mathrm{x}$ is the distance down the pore where the photoelectron is born.

The last term $R \cot \theta / \mathrm{mfp} \operatorname{can}$ be rewritten $\cos \theta(\mathrm{R} / \mathrm{mfp} \sin \theta)$, with the first term representing geometric foreshortening of the pore entrance and the second term representing the ratio of the $x$-ray path length admitting electron escape $(R / \sin \theta)$ to the photon mean free path (see Fig. 3). This term is valid as long as it is $<<1$, true for all reasonable vaues of $\mathrm{R} / \mathrm{mfp}$ (e.g. $\approx 300 \AA / 3 \mu \mathrm{m} \approx .01$ at a few $\mathrm{keV}$ ) for angles > a few degrees.

In the limit of low photon energy $(<5 \mathrm{keV})$, the $\mathrm{mfp}$ is $<<\mathrm{d} / \sin \theta$, hence by Eq. (2), the only significant interaction is at the first pore wall surface $(n=0)$. Eq. (10) then simplifies to:

$\mathrm{Q}_{\mathrm{hv}<5 \mathrm{keV}} \sim \mathrm{I}_{0} \mathrm{G}_{0} \mathrm{SR} \cot \theta / \mathrm{mfp}$

where $G_{0}$ is the full gain experienced by photoelectrons liberated near the top of the plate $(x \approx 0)$. This $\cot \theta$ law breaks down only for small angles $\tan \theta<(D-d) / L\left(\theta<1.5^{\circ}\right.$ 
for a typical MCP L/D ratio of 40) when some rays can enter and exit through a single pore without interacting with the pore walls ("bore-sighted"). For all angles above $2^{\circ}$ where the $\cot \theta$ law is valid, we are also justified in ignoring total external reflection for photon energies above $1 \mathrm{keV}$.

In the limit of high-energy when the photon $\mathrm{mfp}$ is $>\mathrm{dL} / \mathrm{D} \cos \theta,(\mathrm{E} \geq 30 \mathrm{keV})$, there is a significant probability that a photon will emerge unabsorbed from the far side of the MCP. The series in Eq. (1) is then limited by the geometric constraint that an $\mathrm{x}-$ ray photon can traverse/interact with no more than $n_{\max }=L \tan \theta / D$ pores before emerging from the bottom side of the plate. Eq. (1) then simplifies to:

$\mathrm{Q}_{\mathrm{hv}>30 \mathrm{keV}} \sim 2 \mathrm{G}(\mathrm{L} \tan \theta / \mathrm{D})(\mathrm{SR} \cot \theta / \mathrm{mfp})=2 \mathrm{GLSR} / \mathrm{Dmfp}$

where $\mathrm{G}$ is the gain averaged over all $\mathrm{x}$. The MCP sensitivity at very high photon energy should therefore be independent of angle of incidence.

The model accounts for an additional feature, the thin (0.5 $\mu$ m-thick) $\mathrm{Cu} / \mathrm{Au}$ plating extending 0.5-1 pore diameter down into the mouth of each channel, serving as the electrical conductor. This region is nominally field-free, so any photoelectrons produced there would not be further amplified and would not contribute to the total signal (hence the nomenclature "end-spoiling"). Conversely, fringing fields may allow collection of these photoelectrons for further amplification. By modelling both cases and comparing to the data at large incidence angles $\left(>45^{\circ}\right)$ where only the end-spoiling is visible to the softer non-penetrating $x$-rays (see Fig. 1), one should be able to distinguish between the two cases.

III. Experimental Procedure 
MCP angular sensitivity measurements were recorded using a Manson x-ray source. The $\mathrm{MCP}(\mathrm{L}=450 \mu \mathrm{m}, \mathrm{D}=12 \mu \mathrm{m}$, pore diameter $=10 \mu \mathrm{m})$ with associated phosphor read-out screen was mounted on a calibrated tilt stage at $\approx 1 \mathrm{~m}$ from the $\mathrm{x}$-ray source. The relative MCP output signal/unit area was recorded by an optical CCD as the x-ray incidence angle was varied between $6-70^{\circ}$ with respect to the channel axis of the MCP. The absolute incidence angle was known to $0.5^{\circ}$ accuracy by finding the characteristic, bore-sighted signal minimum defining $0^{\circ}$ incidence. Two principal photon energies were used, $\mathrm{Al} \mathrm{K} \mathrm{K}_{\alpha}$ at $1.49 \mathrm{keV}$ and $\mathrm{Ni} \mathrm{K}_{\alpha}$ at $7.47 \mathrm{keV}$, filtered with thin $\mathrm{Al}$ and Co foils respectively. These photon energies have a calculated $1.5 \mu \mathrm{m}$ and $15 \mu \mathrm{m}$ mfp respectively in the MCP glass (see Fig. 3), with the latter allowing for multiple pore interactions along a single ray path. The MCP bias voltage was varied between $500 \mathrm{~V}$ and $1 \mathrm{kV}$, corresponding to near unity gain $\left(\mathrm{V}_{0} \approx 500 \mathrm{~V}\right)$ and high gain respectively. The phosphor screen was kept at a constant potential of $3 \mathrm{kV}$. The purity of the $\mathrm{K}_{\alpha}$ spectra were checked by an identically filtered silicon/lithium detector mounted on a reference arm.

IV. Results

The MCP sensitivity $\mathrm{Q}$ to $1.5 \mathrm{keV} \mathrm{Al} \mathrm{K \alpha}$ photons in signal / unit area is plotted vs. incidence angle relative to the pore axis in Fig. 4 for 500 and $1000 \mathrm{~V}$ bias. Overplotted are results from the $2 \mathrm{D}$ modelling described above assuming either no end-spoiling or a field-free end-spoiling region extending $1 / 2$ pore diameter down. The parameters used in the calculations are $\mathrm{V}_{0}=500 \mathrm{~V}, \mathrm{~L}=450 \mu \mathrm{m}, \mathrm{D}=12 \mu \mathrm{m}$ and $\mathrm{d}=4.4 \mu \mathrm{m}$. In addition, the simple $\cot \theta$ limit for low photon energy, no end-spoiling and unity gain is also plotted for the $500 \mathrm{~V}$ low gain case (Fig. $4 \mathrm{~b}$ ). The calculations have been normalized to the data points at the low angles $\left(6-8^{\circ}\right)$ typical of $\mathrm{MCP}$ routine operation. The relative 
signal strength between gain settings as plotted is arbitrary, but absolute signals do closely follow Eq. (3). As expected, the calculations with and without end-spoiling diverge at large angles, with the $500 \mathrm{~V}$ data being in better agreement with calculations including a field-free region extending $1 / 2$ pore diameter down. This large angle regime was the operating mode for the MCPIGS detectors ${ }^{2}$ used extensively for soft $\mathrm{x}$ ray laser research ${ }^{3}$. To improve detection efficiency, a negative bias placed above the MCP was sometimes added to collect photoelectrons born in the end-spoiling region. At $1000 \mathrm{~V}$ bias, the sensitivity falls slower than $\cot \theta$ because the average birth depth $\mathrm{x}$ (gain by Eq. (3)) for photoelectrons decreases (increases) as the incidence angle increases by Eq. (2). The agreement at $1000 \mathrm{~V}$ bias without a field-free region is better, suggesting fringing fields are more important at higher voltage.

Fig. 5 shows the same type of data and calculations for a $7.5 \mathrm{keV}$ photon energy. We note the further departure from a simple $\cot \theta$ law at this penetrating $(15 \mu \mathrm{m} \mathrm{mfp}) \mathrm{x}$-ray energy. The sensitivity at large angles of incidence is proportionately greater with penetrating $\mathrm{x}$-rays because more pores can be traversed, leading to more pore wall interactions, at larger incidence angles. The calculational differences with and without inclusion of end-spoiling are less significant since the $7.5 \mathrm{keV}$ photons can enter and exit multiple pore walls at large angles of incidence.

In Fig. 6, we plot the predicted angular MCP sensitivities for a range of photon energies representing current and future x-ray line sources (Al, Ti, Zn, Mo, and Sn He-like 2-1 resonance lines at 1.5, 4.75, 9, 18 and $26 \mathrm{keV}$ with $\mathrm{mfps}=1.5,5,25,45$, and $115 \mu \mathrm{m}$, respectively). All calculations are done for a bias of $750 \mathrm{~V}$ representing the typical average bias experienced during gated MCP operation. The Eq. (6) limit of angleindependent sensitivity is approached at high photon energies. 
It is now instructive to assess how different the MCP angular sensitivity will be in gated vs dc operation. Amplification of photoelectrons produced near the top of the pores occurs over a longer transit time $\tau \sim(\mathrm{L}-\mathrm{x}) / \sqrt{ } \mathrm{V}$, hence such an amplification will occur at a lower average voltage (hence lower gain per dynode) for a simple voltage pulse rising to $\mathrm{V}_{\max }$ and falling. Since the gain per dynode is roughly linear with voltage and the transit time per dynode is only weakly dependent on voltage, we can then approximate the transit-time-dependent gain as:

$G_{n}(x)=\left(\frac{V_{\max }(1+x / L)}{2 V_{0}}\right)^{L / 4 D(1-x / L)}$

where it is assumed that the amplification of photoelectrons born between the pore ends $\mathrm{x}=0$ and $\mathrm{x}=\mathrm{L}$ experience a maximum average bias increasing between a realistic $\mathrm{V}_{\max } / 2$ at $\mathrm{x}=0$ and $\mathrm{V}_{\max }$ at $\mathrm{x}=\mathrm{L}$ respectively. Eq. (7) shows that in general there will be a non-zero photoelectron birth depth $\mathrm{x}$ under pulsed operation for which the total gain is maximized. Fig. 7 compares the dc vs pulsed angular sensitivity incorporating in turn Eq. (3) and (7) in Eq. (1). As expected, the drop in sensitivity with incidence angle is greater in pulsed operation because the average photon-wall interaction depth $x$ decreases as $\theta$ increases, reducing the average dynode gain by Eq. (7).

The other quantity of interest is the MCP quantum efficiency $\eta$, which is directly related to $Q$ by:

$\eta \sim Q \Sigma I_{n} / S_{0} \cos \theta \Sigma I_{n} G_{n}=(2 R / D)(d / 2 m f p \sin \theta) / \tanh (d / 2 m f p \sin \theta)$ 
where $1 / \tanh (d / 2 m f p \sin \theta)$ represents the converged limit of the Eq. (2) sum for $2 n+1$ pore wall interactions, valid for photon energies $<30 \mathrm{keV}$ for finite MCP thickness. For non-penetrating $\mathrm{x}$-rays $(\mathrm{d}>\mathrm{mfp}$ and hence $\mathrm{E}<3 \mathrm{keV}$ ), the $1 /$ tanh term is $\approx 1$ at all angles, and Eq. (8) shows that one can double $\eta$ by simply halving the incident angle from say 6 to $3^{\circ}$. This strategy would be most applicable where the MCP detector can subtend a small solid angle to the x-ray source, hence avoiding bore-sighting over part of the detector. For moderately penetrating $x$-rays $(d / 2 m f p \sin \theta<1)$, the quantum efficiency remains constant with incidence angle by Eq. (8). For x-rays traversing the full MCP, Eq. (8) as derived from Eq. (6) becomes $~ 1 / \cos \theta$, providing increased quantum efficiency with increasing incidence angle; however the spatial blurring = $\operatorname{Dmfp} \sin \theta / \mathrm{d}$ at the detector plane will also increase. Finally, the present $\eta(\theta)$ determination can be combined with absolute measurements of $\eta(h v)$ at a given angle of incidence to provide a complete understanding of MCP operation. Such absolute calibrations are best done in photon counting mode using a tunable calibrated synchrotron source ${ }^{13}$.

V. Summary

The angular sensitivity of MCP to x-rays, of importance for a variety of spectroscopic and imaging applications, has been measured for select photon energies and gain. The results are accurately fitted by using a simple $2 \mathrm{D}$ approximation to the $3 \mathrm{D} \mathrm{MCP}$ geometry and by averaging over all possible photon ray paths. The role of the conductive end-spoiling has been elucidated, and provides a smaller than expected effect due to a combination of fringing fields and x-ray pore wall penetration. The simple model can be extrapolated to pulsed operation, higher photon energies and 
novel membraned $\mathrm{MCPs}^{16}$ to provide predictive detector capabilities for future experiment and MCP designs.

\section{References}

${ }^{1}$ J.D. Kilkenny, Lasers and Part. Beams 9, 49 (1991).

${ }^{2}$ M.J. Eckart, R.L. Hanks, J.D. Kilkenny, R. Pasha, J.D. Wiedwald, J. D.Hares, Rev. Sci. Instrum. 57, 2046 (1986).

${ }^{3}$ D.L. Matthews et. al., Phys. Rev. Lett 54, 110 (1985).

${ }^{2}$ P.M. Bell et. al., in Ultrahigh Speed and High Speed Photography, Photonics, and Videography '89, SPIE Vol. 1155 (SPIE, Bellingham WA, 1989), p. 430.

${ }^{3}$ M. Katayama et. al., Rev. Sci. Instrum. 62, 124 (1991).

${ }^{4}$ D.K. Bradley et. al., Rev. Sci. Instrum. 63, 4813 (1992).

${ }^{5}$ F. Ze et. al., Rev. Sci. Instrum. 63, 5124 (1992).

${ }^{6}$ C. Back, R.L. Kauffman, P.M. Bell, and J.D. Kilkenny, Rev. Sci. Instrum. 66, 764 (1995).

${ }^{7}$ O.L. Landen et. al., this proceedings.

${ }^{8}$ D.R. Marsh, O.H.W. Siegmund, and J. Stock, in EUV, X-ray, and Gamma-Ray Instrumentation for Astronomy IV, SPIE Vol. 2006 (SPIE, Bellingham WA, 1993), p. 51.

${ }^{9}$ P. J. Bjorkholm, L. P. VanSpeybroeck, M. Hecht, SPIE 106, 189 (1977).

${ }^{10}$ G. W. Fraser, M. A. Barstow, J. F. Pearson, M. J. Whiteley, M. Lewis, Nucl. Inst. and Meth. 224, 272 (1984).

${ }^{11}$ J. E. Bateman, Nucl. Inst. and Meth. 144, 537 (1977).

${ }^{12}$ T. Tabata, R. Ito, S. Okabe, Nucl. Inst. and Meth. 103, 85 (1972).

${ }^{13}$ N. Yamaguchi, T. Cho, T. Kondoh, M. Hirata, S. Miyoshi, S. Aoki, H. Maezawa, M. Nomura, and Y. Satow, Rev. Sci. Instrum. 60, 2307 (1989).

${ }^{14}$ J.L. Wiza, Nucl. Inst. and Meth. 162, 587 (1979).

${ }^{15}$ P. Eberhardt, Appl. Opt.. 18, 1418 (1979). 
${ }^{16}$ F. Ze, O.L. Landen, P.M. Bell, R.E. Turner, T. Tutt, S.S. Alvarez, and R.L. Costa, Rev. Sci. Instrum. 70, 659 (1999). 
Figure Captions

Figure 1 Cross-sectional schematic of MCP, labelling various parameters used in model.

Figure 2 Top (bore-sighted) view of MCP pores for a) 3D reality and b) 2D model.

Figure 3 Photon mean free path in leaded glass MCP material vs photon energy.

Figure 4 Angular sensitivity of $\mathrm{L} / \mathrm{D}=40, \mathrm{D}=12 \mu \mathrm{m} \mathrm{MCP}$ at $1.5 \mathrm{keV}$ photon energy for dc voltage biases of a) $500 \mathrm{~V}$ and b) $1000 \mathrm{~V}$ bias. The dots are the data, solid and dashed curves are $2 \mathrm{D}$ model predictions $\left(\mathrm{V}_{0}=500 \mathrm{~V}, \mathrm{~d}=7.6 \mu \mathrm{m}\right)$ with and without $3.8 \mu \mathrm{m}$ of end spoiling, and dot-dash line is $\cot \theta$ limit. All curves are normalized to data at $6-8^{\circ}$.

Figure 5 Angular sensitivity of $\mathrm{L} / \mathrm{D}=40, \mathrm{D}=12 \mu \mathrm{m} \mathrm{MCP}$ at $7.5 \mathrm{keV}$ photon energy for dc voltage biases of a) $500 \mathrm{~V}$ and b) $1000 \mathrm{~V}$ bias. The dots are the data, solid and dashed curves are $2 \mathrm{D}$ model predictions $\left(\mathrm{V}_{0}=500 \mathrm{~V}, \mathrm{~d}=7.6 \mu \mathrm{m}\right)$ with and without $3.8 \mu \mathrm{m}$ of end spoiling. All curves are normalized to data at $6-8^{\circ}$.

Figure 6 2D model predictions of angular sensitivity for various photon energies for dc voltage bias of $750 \mathrm{~V}$. Thick solid, thick dashed, thin dotted, thin dashed, and thin solid lines are for $\mathrm{h} v=1.5,4.7,9,18,26 \mathrm{keV}$ respectively.

Figure 7 Comparison of 2D models of pulsed (dashed line) vs dc (solid line) angular sensitivity for a) $1.5 \mathrm{keV}$ (thick lines) and b) $7.5 \mathrm{keV}$ photons (thin lines). Pulsed peak voltage assumed is $1500 \mathrm{~V}$, with average voltage experienced by photoelectron liberated at top of pore being set at $750 \mathrm{~V}$. DC voltage comparison is at $750 \mathrm{~V}$, normalized by factor of 2 to pulsed operation gain at $6^{\circ}$ for clearer comparison. 


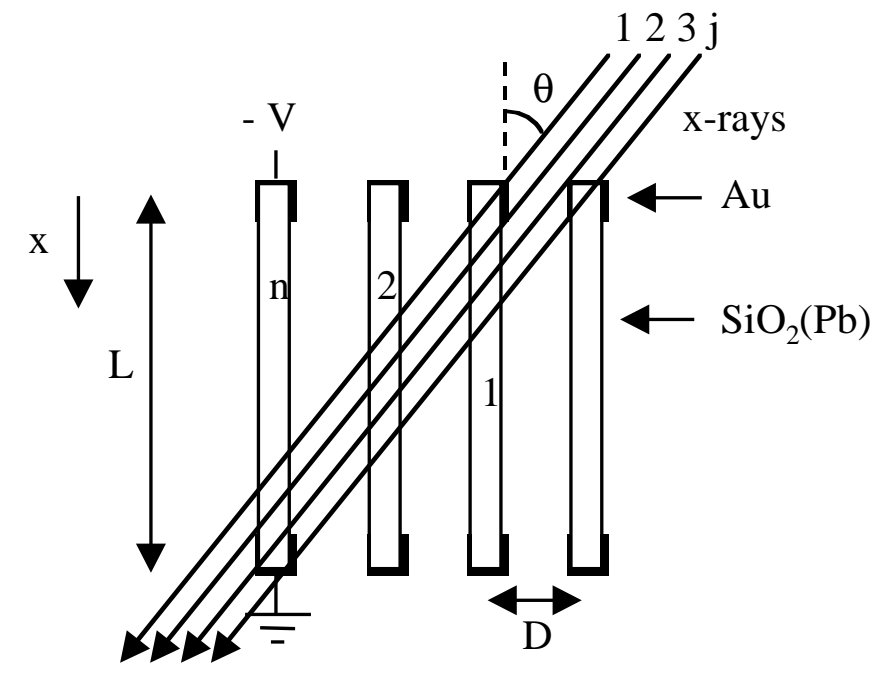

Figure 1

Otto L. Landen, RSI 

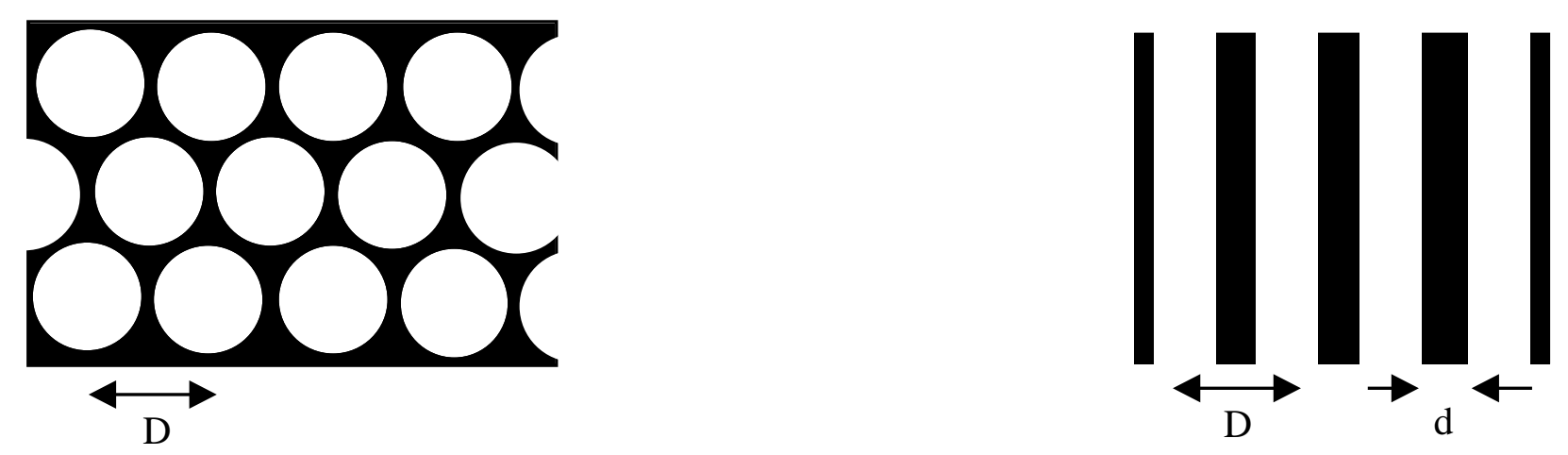

Figure 2 


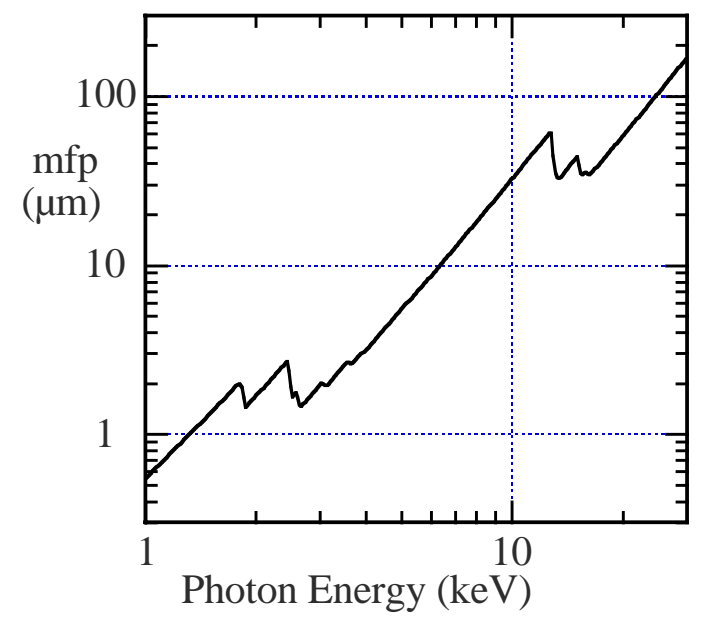

Figure 3

Otto L. Laden, RSI 
a)

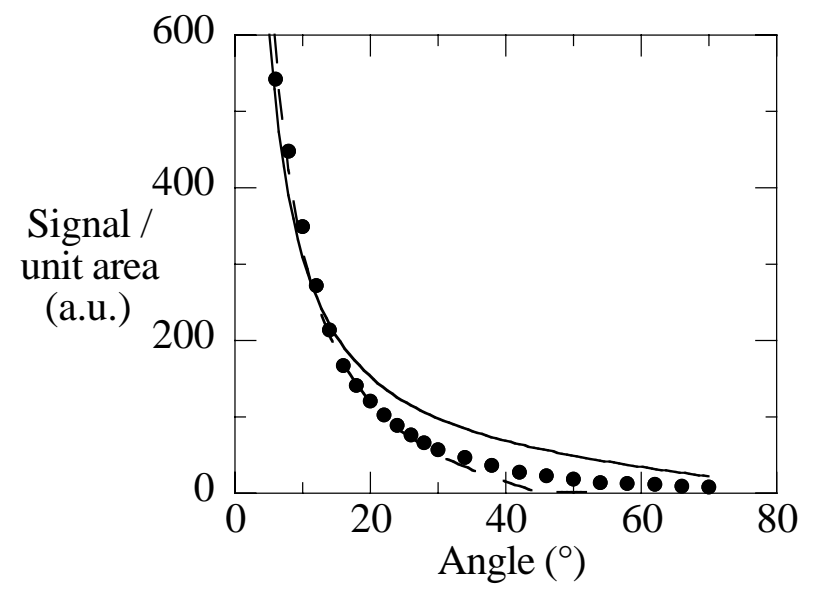

b)

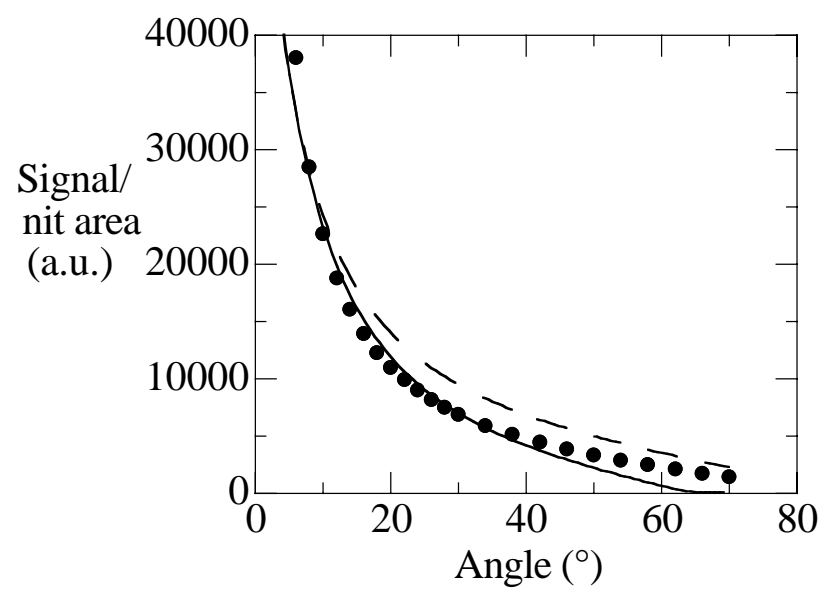

Figure 4 
a)

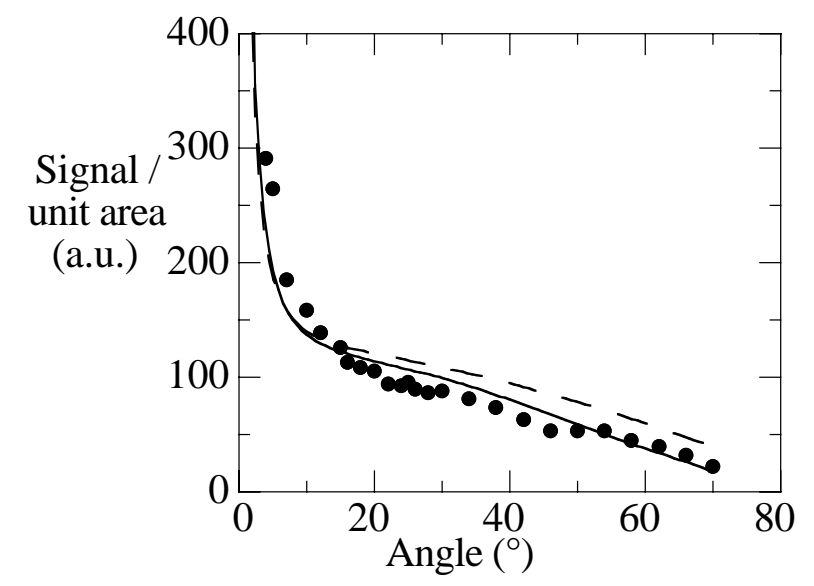

b)

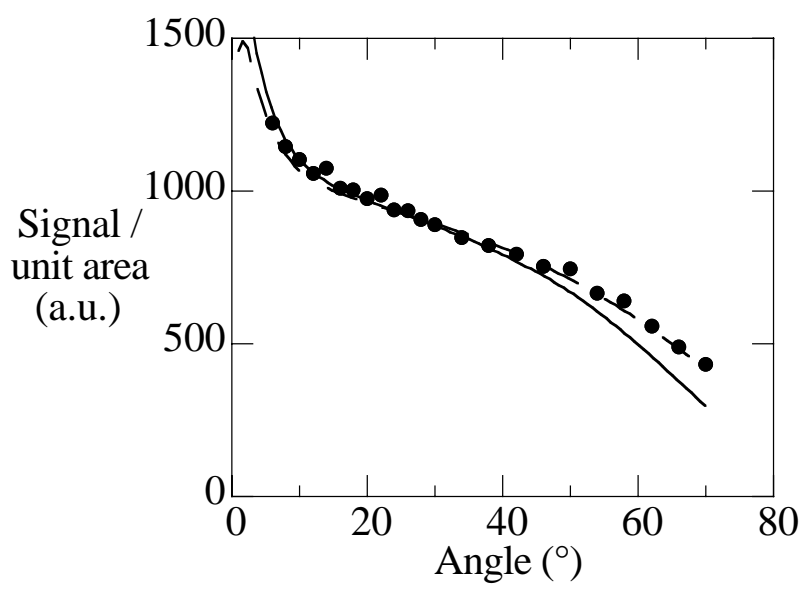

\section{Figure 5}




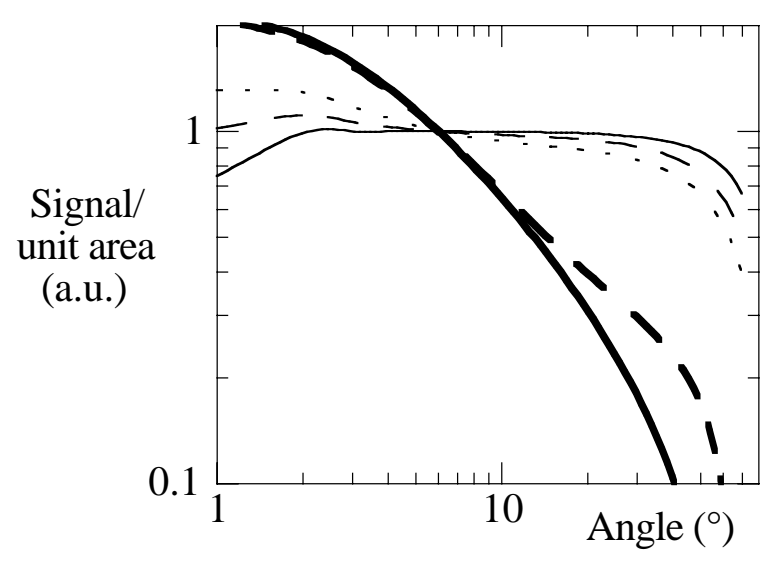

Figure 6 


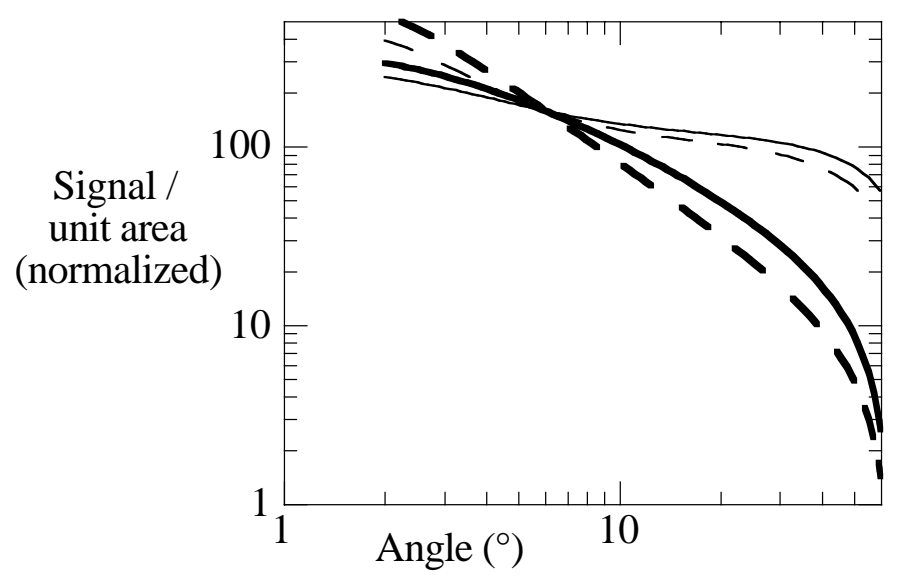

Figure 7

Otto L. Landen, RSI 